\title{
Pengaruh Blending Biofuel dari Minyak Jelantah Terhadap Kerosin
}

\author{
Effect of Blending Biofuel from Waste Cooking Oil on Kerosene
}

\author{
Irma Andrianti ${ }^{1 *}$, Junety Monde ${ }^{1)}$, Akhmad Fauzan ${ }^{1)}$, Lorianti $^{1)}$ \\ ${ }^{1)}$ STT Migas Balikpapan, Program Studi Teknik Perminyakan \\ ${ }^{1)}$ STT Migas Balikpapan, Program Studi Teknik Pengolahan Migas \\ ${ }^{1)}$ STT Migas Balikpapan, Program Studi Teknik Pengolahan Migas \\ ${ }^{1)}$ STT Migas Balikpapan, Program Studi Teknik Pengolahan Migas \\ *email: penulis andrianti.irma@gmail.com,
}

Received: 30/11/19; Revised: 31/12/19; Accepted: 31/12/19

\begin{abstract}
Abstrak
Sumber energi terbarukan semakin mendapat perhatian, hal ini disebakan karena berkurangnya cadangan minyak dan meningkatnya kesadaran manusia akan lingkungan. Biofuel secara umum adalah bahan bakar berasal dari tumbuhan dan hewan. Blending adalah suatu proses pencampuran untuk mendapatkan produk yang memenuhi spesifikasi. Pada penelitian ini metode yang digunakan adalah blending biofuel dengan kerosin yang bertujuan untuk mengetahui karakteristik perbandingan rasio blending biofuel dengan kerosin. Analisa yang dilakukan dalam penelitian ini adalah bilangan asam, massa jenis, bilangan penyabunan, flash point, distilasi, dan bilangan iodin. Variabel penelitian rasio blending 5:95, 10:90, 15:85, 20:80, 25:75, 30:70. Nilai terbaik pada penelitian ini terdapat pada blending dengan rasio B30, bilangan asam diperoleh rasio blending B30 0,08 mg/gram, massa jenis pada rasio blending $\mathrm{B} 30800 \mathrm{Kg} / \mathrm{m}^{3}$, bilangan penyabunan pada rasio blending $\mathrm{B} 302,24 \mathrm{mg} / \mathrm{gram}$, flash point terbaik pada rasio blending $\mathrm{B} 3051{ }^{\circ} \mathrm{C}$, distilasi $90 \%$ pada rasio blending $\mathrm{B} 30298{ }^{\circ} \mathrm{C}$ dan bilangan iodin pada rasio blending $\mathrm{B} 30$ 0,75 gram $\mathrm{I}_{2} /$ gram minyak.
\end{abstract}

Kata kunci: Biofuel, Kerosin, Minyak Jelantah, Rasio

\begin{abstract}
Renewable energy sources are increasingly gaining attention. This is caused due to reduced oil reserves and increased human awareness of the environment. Biofuels, in general, are fuels derived from plants and animals. Blending is a mixing process to get products that meet specifics. In this research method used is blending. Biofuel blending with kerosene is carried out in order to determine the characteristics of the ratio of biofuel blending ratio to kerosene. The analysis carried out in this research is acid number, density, saponification number, flash point, distillation, and iodine number. With research variables blending ratio 5:95, 10:90, 15:85, 20:80, 25:75, 30:70. The best value in this study is in the blending ratio B30, acid number obtained B5 blending ratio $0.084 \mathrm{mg} / \mathrm{gram}$, the best density at the $B 30$ blending ratio $800 \mathrm{~kg} / \mathrm{m} 3$, the best saponification number in the blending ratio B30 $2.24 \mathrm{mg} / \mathrm{gram}$, the best flash point at the $B 3051^{\circ} \mathrm{C}$ blending ratio, the best $90 \%$ distillation at the B10 B30 blending ratio $240298{ }^{\circ} \mathrm{C}$ and the best iodine number at the B30 blending ratio 0.75 gram $I_{2}$ /gram of oil.
\end{abstract}

Keywords: Biofuel, Kerosene, Ratio, Waste Cooking Oil 


\section{PENDAHULUAN}

Sumber energi terbarukan semakin mendapat perhatian, hal ini disebakan karena berkurangnya cadangan minyak dan meningkatnya kesadaran manusia akan lingkungan. Salah satu sumber energi terbarukan adalah berasal dari minyak sayur atau biasa kita sebut minyak nabati (Darmaningsih $d k k$., 2019).

Minyak nabati adalah bahan bakar non-fosil yang dapat ditransesterifikasi untuk biodiesel, yang merupakan bahan bakar alternatif untuk mesin diesel. Minyak goreng bekas dapat digunakan sebagai bahan baku dalam proses pembuatan biodiesel (Darmaningsih $d k k$., 2019). Minyak goreng bekas mengandung asam lemak bebas (Free Fatty Acid, FFA) yang dihasilkan dari reaksi oksidasi dan hidrolisis pada saat penggorengan yang dapat dilihat pada Gambar 1 (Darmaningsih $d k k ., 2019$ ).

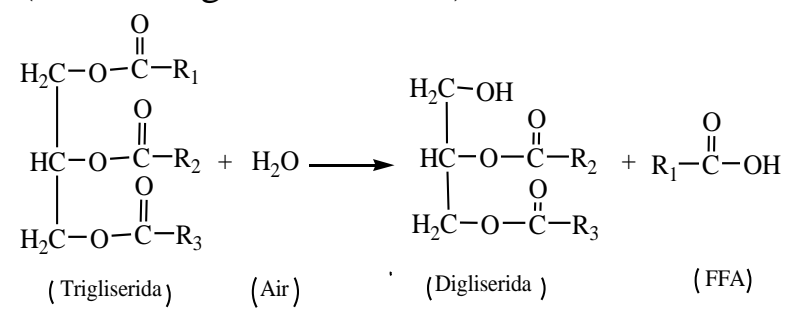

Gambar 1. Reaksi Hidrolisis

Penggunaan minyak nabati pada pembuatan biofuel dapat mengurangi emisi gas buang mesin/kendaraan bermotor dan dapat mengurangi pemanasan global, dikarenakan minyak nabati memiliki kandungan sulfur yang rendah dan memiliki kemampuan terurai yang tinggi pada lingkungan (Blin $d k k$., 2013). Minyak sawit mentah (Crude Palm Oil) melalui proses transesterifikasi, yang secara kimia bereaksi dengan alkohol seperti metanol atau etanol untuk memproduksi biodiesel (Emeji $d k k .$, 2015).
Biodiesel merupakan bahan bakar yang ramah terhadap lingkungan. Biodiesel tidak mengandung berbahaya seperti $\mathrm{Pb}$, bersifat biodegradable, emisi gas buangnya juga lebih rendah dibandingkan emisi bahan bakar diesel (Knothe $d k k$., 2005).

Transesterifikasi adalah suatu reaksi yang menghasilkan ester yang salah satu pereaksinya juga merupakan senyawa ester (Aziz dkk., 2012). Jadi disini terjadi pemecahan senyawa trigliserida dan migrasi gugus alkil antara senyawa ester. Ester yang dihasilkan dari reaksi transesterifikasi ini disebut biodiesel (Knothe \& Razon, 2017).

Reaksinya adalah sebagai berikut :

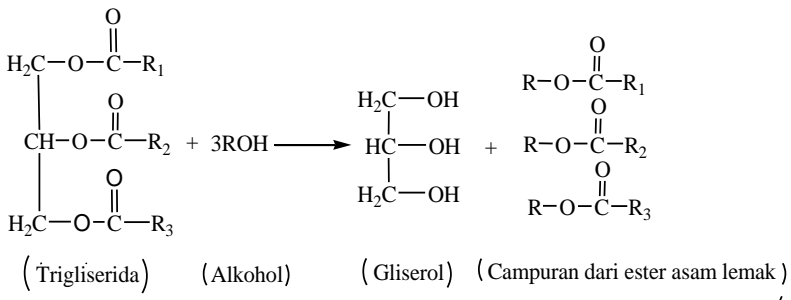

Gambar 2. Reaksi Transesterifikasi

Kerosin umumnya digunakan sebagai bahan bakar rumah tangga (minyak (3)kompor) dan sebagai minyak lampu, dalam hal ini bahan bakar disediakan melalui sumbu-sumbu atau disemprotkan dengan tekanan dan dikabutkan sebelum dibakar, dalam penggunannya sebagai bahan bakar (Panduan pertamina, 1989). Minyak bumi biasanya mengandung $5-25 \%$ kerosin, sedangkan dalam kerosin mengandung senyawa-senyawa seperti parafin, naftan, aromatik, dan senyawa belerang. Jumlah kandungan komponen senyawa dalam kerosin akan mempengaruhi sifat-sifat kerosin (Foidl $d k k .$, 1996).

Proses blending adalah proses mencampurkan dua produk atau lebih ke dalam suatu sistem sehingga menghasilkan suatu produk yang memenuhi spesifik 
(Seto dkk., 2016). Proses blending memiliki banyak manfaat, salah satunya mengubah produk yang mempunyai mutu rendah menjadikan produk yang bermutu tinggi dan mendapatkan produk baru dari produk-produk yang ada (Karuana $d k k$., 2018).

Blending biofuel dari minyak jelantah dengan kerosin bertujuan untuk mengetahui karakteristik fisik seperti bilangan asam, angka penyabunan, flash point, destilasi, massa jenis dan bilangan iodin. Dengan variasi blending B5, B10, B15, B.20, B25 dan B30.

\section{METODE PENELITIAN}

\section{Alat}

Corong Pemisah, kertas saring, Hot Stirrer, Erlenmeyer, alat destilasi, Piknometer.

\section{Bahan}

$\mathrm{NaOH}$, Metanol, Minyak Jelantah, kerosin, $\mathrm{KOH} 0,1 \mathrm{~N}$, indikator penoftalin, labu ukur, $\mathrm{HCl} 0,5 \mathrm{~N}, \mathrm{Na}_{2} \mathrm{~S}_{2} \mathrm{O}_{3} 0,1 \mathrm{~N}, \mathrm{KI}$

\section{Proses Transesterifikasi}

$\mathrm{NaOH} 2,5 \%$ dilarutkan dalam 100 $\mathrm{mL}$ metanol kemudian dicampurkan dalam $500 \mathrm{~mL}$ minyak jelantah. Laju pengadukan diatur sebesar 500 rpm. Reaksi dibiarkan selama 90 menit dan suhunya dijaga konstan sebesar $55{ }^{\circ} \mathrm{C}$. Hasil reaksi dimasukkan ke dalam corong pemisah dengan menggunakan kertas saring, kemudian dibiarkan selama 12 jam sampai terjadi pemisahan yang sempurna. Lapisan atas menunjukkan biodiesel dan lapisan bawah menunjukkan crude gliserol. Selanjutnya lapisan biofuel dipisahkan dan dicampurkan katalis $\mathrm{Pt} / \mathrm{Al}$ sebesar 5 gram yang merupakan katalis heterogen. Campuran dipanaskan pada suhu $55{ }^{\circ} \mathrm{C}$ dengan waktu 90 menit agar metanol menguap. Selanjutnya, pada artikel ini, hasil proses transesterifikasi disebut dengan biofuel.

\section{Proses Pembuatan Sampel Campuran Biofuel dengan Kerosin}

Setelah selesai membuat biofuel, langkah selanjutnya adalah melakukan blending dengan kerosin. Sampel ini nantinya digunakan untuk mengetahui pengaruh komposisi campuran terhadap sifat fisik biodiesel. Hasil blending selanjutnya disebut dengan biodiesel. Adapun variasi blending biofuel dengan kerosin dapat dilihat pada Tabel 1.

Tabel 1. Variasi Pencampuran Biofuel dengan Kerosin

\begin{tabular}{ccc}
\hline Sampel & \multicolumn{2}{c}{$\begin{array}{c}\text { Variasi Komposisi } \\
\text { Campuran }\end{array}$} \\
\hline & Biofuel & Kerosin \\
\hline B5 & 5 & 95 \\
B10 & 10 & 90 \\
B15 & 15 & 85 \\
B20 & 20 & 80 \\
B25 & 25 & 75 \\
B30 & 30 & 70 \\
\hline
\end{tabular}

\section{Karakteristik Biodiesel}

Biodiesel yang telah dihasilkan, diuji sifat fisik seperti bilangan asam, angka penyabunan, flash point, destilasi, massa jenis dan bilangan iodin.

\section{Uji Bilangan Asam}

Biodiesel sebanyak 5 gram dimasukkan ke dalam Erlenmeyer dan ditambahkan $50 \mathrm{~mL}$ metanol $95 \%$. Kemudian dipanaskan menggunakan Hot Stirrer hingga mendidih sambil diaduk sampai terbentuk larutan homogen. Setelah dingin, ditambahkan indikator penoftalin sebanyak 3 tetes, kemudian larutan dititrasi dengan $\mathrm{KOH} \quad 0,1 \quad \mathrm{~N}$ sampai terbentuk warna merah jambu yang tidak hilang 
selama 30 detik (Nurhasnawati $d k k$., 2015).

Bilangan asam dihitung dengan perhitungan berikut :

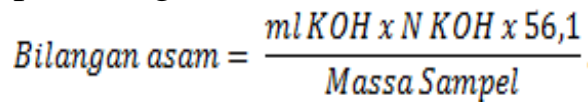

\section{Angka Penyabunan}

Sampel biodiesel ditimbang sebanyak 5 gram, kemudian dimasukkan ke dalam Erlenmeyer $250 \mathrm{~mL}$ dan ditambahkan $50 \mathrm{~mL}$ larutan $\mathrm{KOH}$ beralkohol. Labu Erlenmeyer disambungkan dengan kondensor berpendingin udara dan larutan di dalam labu dididihkan dengan suhu $40{ }^{\circ} \mathrm{C}$ selama 60 menit hingga sampel tersabun sempurna. Larutan yang diperoleh pada akhir penyabunan harus jernih dan homogen. Larutan dibiarkan cukup dingin, kemudian dinding dalam kondensor dibilas dengan aquades. Labu dilepaskan dari kondensor lalu larutan di dalam labu dititrasi dengan $\mathrm{HCl} 0,5 \mathrm{~N}$ sampai warna merah jambu hilang minimal selama 15 detik.

Bilonganperyabunon $=\frac{56,1 x(\mathrm{Vb}-\mathrm{Vc}) x N}{\mathrm{~m}}$

Bs : bilangan sabun (mg KOH/g biodiesel)

$\mathrm{Vb}$ : volume $\mathrm{HCl}$ untuk titrasi blanko $(\mathrm{ml})$

$\mathrm{Vc}$ : volume $\mathrm{HCl}$ untuk titrasi sampel (ml)

$\mathrm{N}$ : normalitas larutan $\mathrm{HCl} 0,5 \mathrm{~N}$

$\mathrm{m}$ : berat sampel biodiesel $(\mathrm{g})$

\section{Uji Flash Point}

Titik nyala atau flash point merupakan nilai yang menyatakan suhu terendah dari bahan bakar minyak untuk bisa menyala jika terkena nyala api (Prasetyo, 2017).

Tahapan-tahapan pengujian flash point campuran biodiesel adalah sebagai berikut :

sampel biodiesel sebanyak $10 \mathrm{~mL}$ ditempatkan pada cawan dan dipanaskan hingga suhu di atas $100{ }^{\circ} \mathrm{C}$, diamati pada suhu berapa sampel biodiesel mulai menyala, dan dicatat hasil pengujian.

\section{Uji Distilasi}

Analisa distilasi untuk memberikan informasi kandungan fraksi ringan dan berat yang disajikan dalam titik didih. Sampel minyak dituangkan ke dalam labu distilasi, kemudian dimasukkan ke dalam alat distilasi dan alat dinyalakan. Selanjutnya, diletakkan gelas ukur di dalam alat distilasi, dan diatur tekanan pada 100 atm. Kemudian ditunggu tetes pertama dan dicatat suhu jika kenaikan per $10 \mathrm{~mL}$.

Pemeriksaan distilasi yang dilakukan untuk biodiesel adalah dengan metode ASTM D-86. Distilasi dilakukan pada volume $100 \mathrm{~mL}$, suhu uap pertama menetes (setelah mengembun) disebut IBP (Initial Boiling Point).

\section{Uji Densitas}

Analisa densitas untuk mengetahui massa jenis suatu produk dengan piknometer $10 \mathrm{~mL}$. Piknometer kosong ditimbang dan minyak $10 \mathrm{~mL}$ dimasukkan ke dalam piknometer. Selanjutnya piknometer yang berisi minyak, ditimbang dan dicatat beratnya.

\section{Uji Bilangan Iodin}

Sampel biodiesel dimasukkan ke dalam Erlenmeyer bertutup, kemudian dipanaskan. Selanjutnya ditambahkan kloroform dan larutan hunus untuk melarutkan sampel minyak dan ditambahkan $25 \mathrm{ml}$ larutan KI 15\%, dikocok secara merata. Labu Erlenmeyer dan tutupnya dicuci dengan $150 \mathrm{~mL}$ akuades yang baru dan dingin, dan cucian 
dimasukkan ke dalam larutan. Selanjutnya dititrasi dengan $\mathrm{Na}_{2} \mathrm{~S}_{2} \mathrm{O}_{3} 0,1 \mathrm{~N}$ dengan pengocokan yang konstan hingga warna kuning hilang, lalu ditambahkan 2 $\mathrm{mL}$ indikator amilum sebagai indikator. Titrasi dilanjutkan hingga warna biru hilang. Bilangan iodin dihitung dengan menggunakan perhitungan berikut :



\section{HASIL DAN PEMBAHASAN \\ Hasil Proses Transesterifikasi}

Minyak jelantah merupakan bahan baku yang digunakan terhadap pembuatan biodiesel. Pembuatan biodiesel dilakukan melalui proses transesterifikasi. Hasil transesterifikasi dilakukan pengujian terhadap sifat fisik seperti bilangan asam, angka penyabunan, flash point, destilasi, densitas dan bilangan iodin dapat dilihat pada Tabel 2.

Tabel 2.Hasil Transesterifikasi

\begin{tabular}{lcccc}
\hline \multirow{2}{*}{ Parameter } & Satuan & Hasil Transesterifikasi & \multicolumn{2}{c}{ Standard Biodiesel } \\
\cline { 4 - 5 } $\begin{array}{l}\text { Bilangan } \\
\text { Asam }\end{array}$ & mg KOH/g minyak & $0,23 \%$ & Max 0,8 & Pengujian \\
$\begin{array}{l}\text { Massa } \\
\text { Jenis }\end{array}$ & $\mathrm{Kg} / \mathrm{m}^{3}$ & 840 & $815-860$ & ASTM D 664 \\
$\begin{array}{l}\text { Bilangan } \\
\text { Penyabunan }\end{array}$ & $\mathrm{Mg} / \mathrm{gram}$ & 10,098 & Min 312 $\mathrm{mg} \mathrm{KOH} / \mathrm{g}$ & ASTM D 6751 \\
$\begin{array}{l}\text { Bilangan } \\
\text { Iod }\end{array}$ & gram I2/100 gram & 2,538 & Maks 115 & SNI Biodiesel \\
$\begin{array}{l}\text { Flash Point } \\
\text { minyak }\end{array}$ & ${ }^{\circ} \mathrm{C}$ & $179.44{ }^{\circ} \mathrm{C}$ & Min 52 & ASTM D 93 \\
\hline
\end{tabular}

\section{Hasil Blending Biofuel dengan Kerosin}

Hasil blending biofuel dengan kerosin dapat dilihat pada Gambar 3.

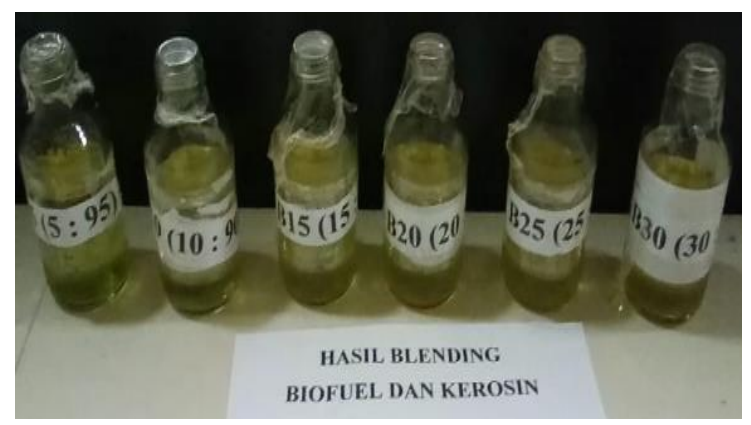

Gambar 3. Hasil Blending dengan Kerosin
Hasil blending dengan pengujian sifat fisik seperti bilangan asam, angka penyabunan, flash point, destilasi, massa jenis dan bilangan iodin dibandingkan dengan nilai standar biodiesel dapat dilihat di Tabel 3. 
Tabel 3. Hasil Uji Sifat Fisik Blending dengan Kerosin

\begin{tabular}{lccccccccc}
\hline Parameter & Satuan & B5 & B10 & B15 & B20 & B25 & B30 & Nilai & Parameter \\
\hline $\begin{array}{l}\text { Bilangan } \\
\text { Asam }\end{array}$ & $\begin{array}{c}\mathrm{mg} \\
\mathrm{KOH} / \mathrm{g} \\
\text { minyak }\end{array}$ & 0,04 & 0,05 & 0,072 & 0,084 & 0,084 & 0,084 & Max 0,8 & ASTM D 664 \\
Massa Jenis & $\mathrm{Kg} / \mathrm{m}^{3}$ & 776 & 778 & 784 & 796 & 800 & 800 & $815-860$ & ASTM D 1298 \\
$\begin{array}{l}\text { Bilangan } \\
\text { Penyabunan }\end{array}$ & $\begin{array}{c}\mathrm{Mg} / \mathrm{gram} \\
\text { gram }\end{array}$ & 3,14 & 2,91 & 2,58 & 2,46 & 2,46 & 2,24 & $\begin{array}{c}\text { Min 312 mg } \\
\text { KOH/g }\end{array}$ & ASTM D 6751 \\
$\begin{array}{l}\text { Bilangan } \\
\text { Iodin }\end{array}$ & $\begin{array}{c}\text { I2/100 } \\
\text { gram }\end{array}$ & 0,4 & 0,45 & 0,65 & 0,75 & 0,75 & 0,75 & Maks 115 & SNI Biodiesel \\
minyak & & & & & & & & \\
$\begin{array}{l}\text { Flash Point } \\
\text { Distilasi }\end{array}$ & ${ }^{\circ} \mathrm{C}$ & 51 & 50,5 & 50,5 & 48,5 & 48,5 & 51 & Min 52 & ASTM D 93 \\
\hline
\end{tabular}

Pengaruh Rasio Blending Biofuel dengan Kerosin Terhadap Angka Asam

Angka asam menunjukkan adanya asam lemak bebas dalam biofuel. Adanya asam lemak bebas dalam biofuel dapat mengakibatkan terbentuknya abu pada saat pembakaran. Angka asam dapat menjadi indikator kerusakan yang terjadi pada biofuel, akibat terjadinya aktivitas oksidasi (Widodo, 2018).



Gambar 4. Pengaruh Rasio Blending Biofuel dengan Kerosin Terhadap Bilangan Asam

Pada Gambar 4 dapat dilihat pengaruh rasio blending terhadap bilangan asam. Pada blending B5, B10, B15, B20, B25 dan B30 diperoleh nilai 0,044, 0,05, 0,072, 0,084, 0,084, dan 0,084 mg/gr.
Semakin tinggi rasio blending biofuel maka nilai angka asam juga akan semakin meningkat.

Pengaruh Rasio Blending Biofuel dengan
Kerosin Terhadap Bilangan Penyabunan

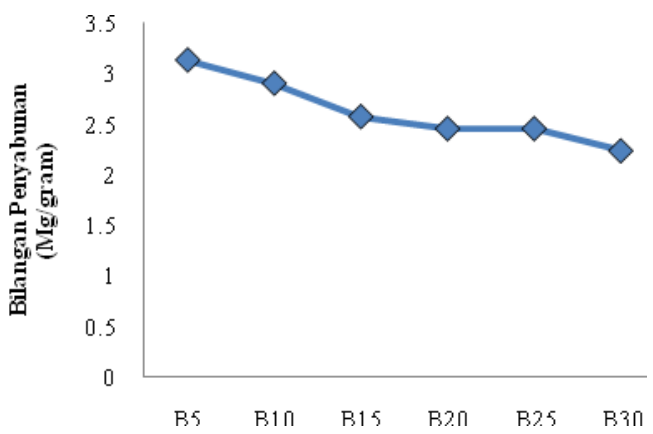

Gambar 5. Pengaruh Rasio Blending Biofuel dengan Kerosin Terhadap Bilangan Penyabunan

Pada Gambar 5 dapat dilihat hubungan rasio blending terhadap bilangan penyabunan. Pada blending B5, B10, B15, B20, B25 dan B30 diperoleh nilai 3,14, 2,91, 2,58, 2,46, 2,46, dan 2,24 mg/gr.

Penggunaan biofuel yang tinggi menunjukkan bilangan penyabunan biodiesel yang dihasilkan dari blending biofuel dengan kerosin menjadi rendah. 
Hal ini dikarenakan rasio biofuel yang tinggi pada blending berdampak pada besarnya berat molekul rata-rata dari biodiesel yang dihasilkan. Semakin besar berat molekul suatu senyawa organik yang sejenis, bilangan penyabunannya akan semakin turun (Munack, 2006).

\section{Pengaruh Rasio Blending Biofuel} dengan Kerosin Terhadap Flash Point

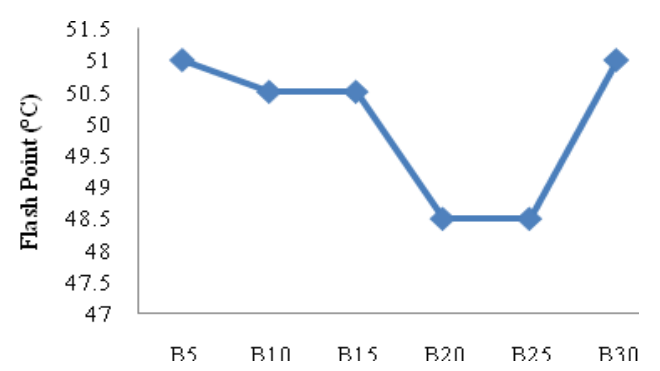

Gambar 6. Pengaruh Rasio Blending Biofuel dengan Kerosin Terhadap Flash Point

Pada Gambar 6 dapat dilihat hubungan rasio blending terhadap flash point. Pada blending B5, B10, B15, B20, $\mathrm{B} 25$ dan $\mathrm{B} 30$ diperoleh nilai $51^{\circ} \mathrm{C}, 50,5$ ${ }^{\circ} \mathrm{C}, 50,5{ }^{\circ} \mathrm{C}, 48,5{ }^{\circ} \mathrm{C}, 48,5{ }^{\circ} \mathrm{C}$ dan $51{ }^{\circ} \mathrm{C}$. Titik nyala atau flash point merupakan suhu terendah dari bahan bakar minyak untuk terbakar saat permukaan minyak tersebut didekatkan dengan sumber api (Susanto, 2016). Semakin banyak rasio biofuel pada blending maka nilai flash point akan semakin rendah.

\section{Pengaruh Rasio Blending Biofuel dengan Kerosin Terhadap Distilasi}

Berdasarkan Gambar 7, temperatur yang dihasilkan pada distilasi $90 \%$ dengan volume biofuel yang dihasilkan pada variasi blending B5, B10, B15, B20, B25 dan B30 adalah sebesar $268{ }^{\circ} \mathrm{C}, 240{ }^{\circ} \mathrm{C}$, $262{ }^{\circ} \mathrm{C}, 262{ }^{\circ} \mathrm{C}, 284{ }^{\circ} \mathrm{C}$ dan $298^{\circ} \mathrm{C}$. Nilai ini memenuhi standar Dirjen Migas No. 978.K/10/DJM.S/2013, yaitu sebesar 370 ${ }^{\circ} \mathrm{C}$.

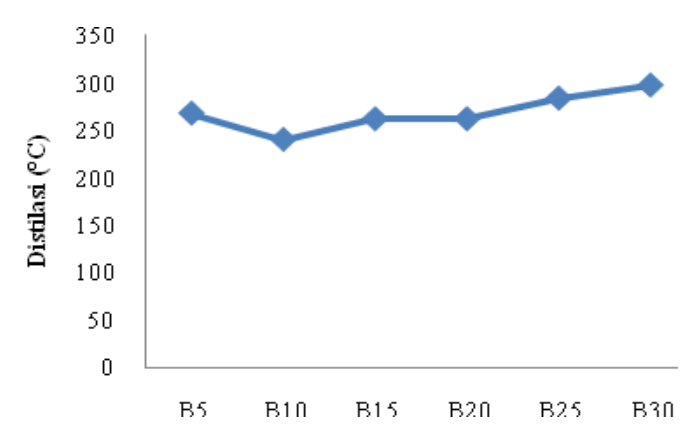

Gambar 7. Pengaruh Rasio Blending Biofuel dengan Kerosin Terhadap Distilasi

\section{Pengaruh Rasio Blending Biofuel dengan Kerosin Terhadap Massa Jenis}

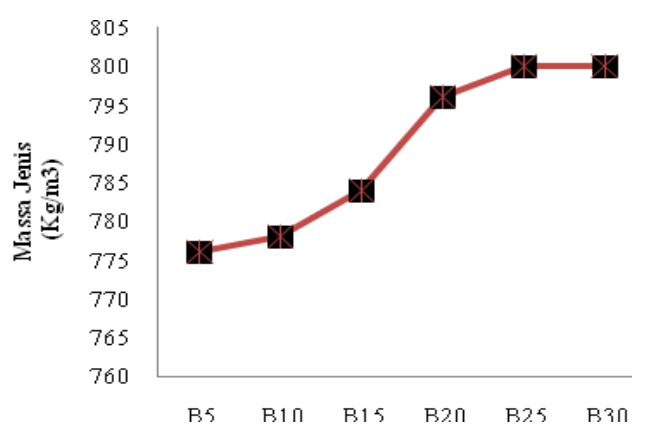

Gambar 8. Pengaruh Rasio Blending Biofuel dengan Kerosin Terhadap Massa Jenis

Massa jenis menunjukkan perbandingan massa persatuan volume. Karakteristik ini berkaitan dengan nilai kalor dan daya yang dihasilkan oleh mesin diesel persatuan volume bahan bakar. Kerapatan suatu fluida ( $\rho)$ dapat didefenisikan sebagai massa per satuan volume. Pada pengaruh rasio blending terhadap massa jenis hasil blending B5, B10, B15, B20, B25, dan B30 diperoleh nilai 776, 778, 784, 796, 800, dan 800 $\left(\mathrm{Kg} / \mathrm{m}^{3}\right)$. 


\section{Pengaruh Rasio Blending Biofuel dengan Kerosin Terhadap Bilangan Iodin}

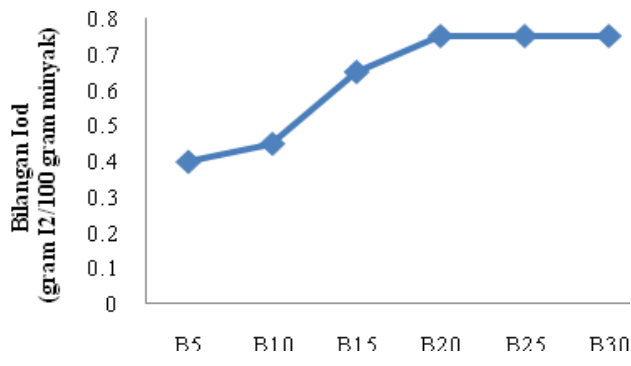

Gambar 9. Pengaruh Rasio Blending Biofuel dengan Kerosin Terhadap Bilangan Iodin

Angka iodin menunjukkan kandungan asam tak jenuh penyusun alkil ester dalam biodiesel. Keberadaan senyawa tak jenuh dapat meningkatkan performansi yaitu meningkatkan angka setana. Bilangan iodin ditentukan oleh tingkat ketidak jenuhan minyak. Apabila tingkat ketidak jenuhan minyak tinggi maka minyak akan mengikat iodin dalam jumlah yang lebih besar sehingga bilangan iodinnya semakin besar. Sedangkan biofuel sendiri berupa senyawa hidrokarbon jenuh, sehingga semakin banyak digunakan dalam rasio blending akan mengakibatkan bilangan iod semakin tinggi. Seperti pada gambar didapatkan hasil bilangan iodin pada blending B5, B10, B15, B20, B25 dan B30 diperoleh nilai $0,4,0,45,0,65,0,75,0,75$, dan 0,75 gr I/ $/$ gram minyak.

\section{KESIMPULAN}

Dari hasil penelitian ini maka dapat diberikan kesimpulan bahwa semakin tinggi rasio blending biofuel maka akan memberikan pengaruh terhadap bilangan asam, angka penyabunan, flash point (titik nyala) dan bilangan iodin.

Nilai terbaik pada penelitian ini terdapat pada blending dengan rasio B30, bilangan asam diperoleh rasio blending B30 0,08 mg/gram, massa jenis pada rasio blending B30 $800 \mathrm{~kg} / \mathrm{m}^{3}$, bilangan penyabunan pada rasio blending B30 2,24 $\mathrm{mg}$ /gram, flash point terbaik pada rasio blending B30 $51{ }^{\circ} \mathrm{C}$, distilasi $90 \%$ pada rasio blending B30 $298{ }^{\circ} \mathrm{C}$ dan bilangan iodin pada rasio blending B30 0,75 gram $\mathrm{I}_{2}$ /gram minyak.

\section{DAFTAR RUJUKAN}

Aziz, I., Nurbayti, S., \& Ulum, B. (2012). Pembuatan produk biodiesel dari Minyak Goreng Bekas dengan Cara Esterifikasi dan Transesterifikasi. Jurnal Kimia VALENSI, 2(3).

Blin, J., Brunschwig, C., Chapuis, A., Changotade, O., Sidibe, S., Noumi, E., \& Girard, P. (2013). Characteristics of vegetable oils for use as fuel in stationary diesel engines-Towards specifications for a standard in West Africa. Renewable and Sustainable Energy Reviews, 22, 580-597.

Darmaningsih, A., Fitriyanti, S. N., Elektro, F. T., \& Telkom, U. (2019). Uji Kalor Bahan Bakar Campuran Solar Dan Minyak Nabati. Uji Kalor Bahan Bakar Campuran Solar Dan Minyak Nabati, 6(1), 1370-1376.

Emeji, I. C., Afolabi, A. S., Abdulkareem, A. S., \& Kalala, J. (2015). Characterization and kinetics of biofuel produced from waste cooking oil. Lecture Notes in Engineering and Computer Science, 2220, 589-592.

Foidl, N., Foidl, G., Sanchez, M., Mittelbach, M., \& Hackel, S. (1996). Jatropha curcas L. as a source for the production of biofuel in Nicaragua. Bioresource Technology, 58(1), 7782. 
Karuana, F., Barus, B. R., Wimada, A. R., Kaddihani, W., \& Diaztuti, M. D. (2018). Kajian Penggunaan Helical Static Mixer Pada In-Line Blending Dalam Proses Pencampuran Biodiesel Dan Minyak Solar Di Area. Prosiding Seminar Nasional Sains dan Teknologi, Universitas Muhammadiyah Jakarta, 17 Oktober 2018.

Knothe, G., Krahl, J., \& Gerpen, J. V. (2005). The Biodiesel Handbook. In The Biodiesel Handbook.

Knothe, G., \& Razon, L. F. (2017). Biodiesel fuels. Progress in Energy and Combustion Science, 58, 36-59.

Munack, A. (2006). Books: Biodiesel - A comprehensive handbook. Martin Mittelbach, Claudia Remschmidt (Ed.). Biotechnology Journal, 1(1), 102-102.

Nurhasnawati, H., Supriningrum, R., \& Caesariana, N. (2015). Penetapan Kadar Asam Lemak Bebas Dan Bilangan Peroksida Pada Minyak Goreng Yang Digunakan Pedagang Gorengan Di Jl. A.W Sjahranie Samarinda. Jurnal Ilmiah Manuntung, 1(1), 25-30.

Panduan Pertamina. 1989. Panduan Pertamina Minyak Bumi.

Prasetyo, Y. (2017). Pengaruh Komposisi Campuran Terhadap Sifat Fisik Biodiesel Dengan Bahan Baku Minyak Jarak Dan Minyak Sawit.Jurnal Tenik Mesin, 5(1), 1-8.

Seto, E. Y., Konnan, J., Olivieri, A. W., Danielson, R. E., \& Gray, D. M. D. (2016). A quantitative microbial risk assessment of wastewater treatment plant blending: Case study in San Francisco Bay. Environmental
Science: Water Research and Technology, 2(1), 134-145.

Susanto, J. M. (2016). Sintesis Biodiesel Dari Minyak Biji Kapuk Randu Dengan Variasi Suhu Pada Reaksi Transesterifikasi Dengan Menggunakan Katalisator Naoh Dan Rasio Minyak/Metanol 15/1. Pelita, $\mathrm{XI}(2)$.

Widodo, R. (2018). Penentuan Bilangan Asam, Penyabunan, Dan Iodium Pada Stearyl Alcohol Sebagai Bahan Tambahan Salep Di Pt. Konimex. Retrieved from https://dspace.uii.ac.id/handle/123456 $789 / 10867$ 